\title{
Veterans' Health Care Utilization in Department of Veterans Affairs Facilities Two to Twelve Years after Applying for PTSD Service Connection: Findings from a Nationally Representative Cohort
}

\author{
Maureen Murdoch, MD, MPH ${ }^{1,2,3}$ \\ Yvonne Jonk, $\mathrm{PhD}^{4}$ \\ ${ }^{1}$ Center for Care Delivery Outcomes Research and ${ }^{2}$ Section of General Internal Medicine, \\ Minneapolis VA Health Care System, Minneapolis, MN \\ ${ }^{3}$ Department of Medicine, University of Minnesota Medical School, Minneapolis, MN \\ ${ }^{4}$ Maine Rural Health Center, Muskie School of Public Health, University of Southern Maine, \\ Portland, Maine
}

\begin{abstract}
Acknowledgements
Funding for this study was provided by the Department of Veterans Affairs (VA) Health Services Research and Development (HSR\&D) Service (IIR 01-118) Dr. Murdoch is a core investigator for the Center for Care Delivery Outcomes Research at the Minneapolis VA Medical Center, which is a VA Health Services Research and Development (HSR\&D) Service Center of Innovation. We thank the CCDOR data group for data management.
\end{abstract}

\section{Tags}

Veterans, Military, Service-Connected, Service Connection, Disability Benefits, Compensation, Compensation Status, Compensation-Seeking, Health, Health Care, Health Care Utilization, Comparative Analysis, Cohort, Prospective, Retrospective, Denied, Awarded, Application 


\begin{abstract}
Background: Critics fear that some Veterans use Department of Veterans Affairs (VA) mental health services solely to establish eligibility for posttraumatic stress disorder (PTSD) disability benefits, then drop out of treatment once their claim is approved. Objective: To examine the long-term effects of receiving VA disability benefits for PTSD on health care in the VA system. Methods: Using VA administrative data, we examined the health care utilization of a nationally representative cohort of former PTSD disability claimants. Veterans filed PTSD disability claims between 1994 and 1998. They returned mailed surveys between 1998 and 2000 (Time 1) and between 2004 and 2006 (Time 2). We examined their health care utilization for the 6 months before and after they received their surveys, comparing the health care use of successful claimants (SC+) to unsuccessful claimants (SC-). Results: Of the 3,337 Veterans in the cohort, 3,090 had at least one episode of care at a VA facility during the study period. Except for rehabilitative services, successful claimants were statistically significantly more likely to have used any outpatient VA service in the year centered on their Time 1 survey than were SCVeterans ( $p$ s $<0.001)$. At Time $2, \mathrm{SC}+$ Veterans were more likely than SC-Veterans to have used any outpatient mental health $(p<0.001)$, primary care $(p<0.01)$ or surgical care $(p<0.05)$ services. Among those using any outpatient services at Time 2 , the intensity of services used by $\mathrm{SC}+$ and SC-Veterans was comparable ( $p s>0.08)$. Hospitalizations were similar in the two groups during both time periods ( $p s>0.11$ ). From Time 1 to Time 2 (a period of 6 to 8 years), $\mathrm{SC}+$ Veterans reduced the average number of mental health stops they made by 4.6 visits per year, whereas SC- Veterans reduced by 2.9 visits per year $(p=0.81)$. Conclusion: On net, more $\mathrm{SC}+$ Veterans used outpatient mental health and other services than did SC- Veterans, and this effect persisted for up to 12 years after Veterans initially filed their claims. These data suggest that PTSD disability benefits facilitate access to and use of mental health and other care in the VA system.
\end{abstract}


In 2016, approximately 880,000 US Veterans received Department of Veterans Affairs (VA) disability benefits for posttraumatic stress disorder (PTSD)[1]. Veterans receiving compensation for disorders incurred or aggravated by their military service, such as PTSD, are service connected for those disorders. The VA rates the severity of Veterans' disability from $0 \%$ (nondisabling) to $100 \%$ (totally disabled); this is called the service connected disability rating or the degree of service connection. Veterans may be service connected for multiple disorders, but their total disability rating can never exceed $100 \%$. Higher ratings are associated with greater compensation and other benefits. Currently the highest service connected rating yields an annual, tax-free, cash benefit of $\$ 36,684$ [https://www.benefits.va.gov/compensation/resources comp01.asp; accessed 3/22/2019]. Veterans with dependents or other special ratings, such as need for aid and attendance, are eligible for still higher cash benefits. All Veterans are eligible for free treatment and medications for any service connected disorder, even if their rating level is $0 \%$.

Critics have periodically raised concerns that some Veterans, in hopes of obtaining a cash benefit, use VA mental health services only long enough to give credence to their PTSD disability claim and then drop out of treatment [2,3]. VA clinicians have also rated Veterans' therapeutic motivations more negatively when they are applying for PTSD disability benefits compared to when they are not applying [4]. Further fueling these concerns, in 2005 the VA's Office of Inspector General showed that $39 \%$ of Veterans in a convenience sample dropped out of treatment once they became service connected at the highest level [5].

However, few investigators have examined Veterans' VA health care utilization after their PTSD disability claim has been adjudicated using representative samples; even then, they have typically examined post-claim use for only a few weeks to months, e.g., [6-8]. To our knowledge, no one has investigated Veterans' health care utilization for more than a year postclaim adjudication. In the present analysis, we report on former PTSD disability applicants' VA health care utilization for up to 12 years after their claim was initially adjudicated.

\section{Methods}

Design. The study is pre-planned, secondary analysis of an ambispective cohort (ambispective = retrospective and prospective elements). The analysis presented here was completed in 2006.

Subjects and Settings. From a sampling frame of 100,750 men and 3,866 women Veterans who applied for VA PTSD disability benefits between 1994 and 1998, we selected 2,700 men and 2,700 women to participate in mailed surveys collected between 1998 and 2000 (Time 1) and between 2004 and 2006 (Time 2). Of these, 3,337 Veterans responded at Time 1. Details of the surveys, including a Time 3 effort, have been reported elsewhere [9-11]. At Time 1, respondents' mean age was $48( \pm 13)$ years. Almost three-fourths $(73 \%)$ self-identified as white, $17 \%$ as black, $7 \%$ as American Indian or Alaskan Native, 5\% as Hispanic, $1 \%$ as Asian American, and $1 \%$ as Native Hawaiian or other Pacific Islander. Five percent reported more than one race/ethnicity. Although 67\% reported at least some college experience, not quite a quarter were working for pay in the two weeks prior to Time 1 . Seven percent of the sample had served during World War II; 4\%, during the Korean Conflict; 49\%, during the Vietnam Conflict; 18\%, after Vietnam; 16\%, during Gulf War I; and 6\%, after Gulf War I. Based on a claims audit of a randomly selected subset of the Veterans $(n=537)$, we estimated that $80 \%$ of the sample had a clinical diagnosis of 
PTSD when they filed their disability claim. All PTSD disability claims had been adjudicated an average of $2.4( \pm 1.2)$ years before Veterans enrolled in the study.

Human Studies Oversight. The Minneapolis VA Medical Center's Subcommitte on Human Studies reviewed and approved the study protocol.

Outcomes. The main study outcome was Veteran's change in VA health care utilization between Time 1 and Time 2. Secondary outcomes examined total use at each time point and use at each time point broken down by mental health, primary care, specialty care, surgical care, or rehabilitation services. Please see the Appendix for stop codes used. Inpatient VA care was examined overall and by psychiatric and medical/surgical inpatient hospitalizations.

Measures. We used the Outpatient Care and Patient Treatment Files files then housed in the VA's Austin Automated Center to assess Veterans' health care utilization. Utilization was measured as the number of "stops" or encounters Veterans made during each time period. Time 1 health care utilization was ascertained for the 6 months preceding and 6 months post ceding Veterans' receipt of the Time 1 survey; Time 2 health care utilization was ascertained for the 6 months preceding and 6 months post ceding their receipt of the Time 2 survey.

Analysis. The analysis considers only those Veterans who had at least one encounter with the VA medical system at Time 1 or Time 2. A total of 273 Veterans died between Time 1 and Time 2 and did not contribute to the primary outcome. For the remaining 3,064 Veterans still alive at Time 2, if they had no health care utilization in one time period but had at least one encounter in the other time period, we gave them a value of zero for the period with no health care use. Study outcomes were compared between those who were service connected for PTSD (SC+) at Time 1 and those who were not (SC-).

\section{Results}

Of the 3,337 Time 1 respondents, 3,090 (92.6\%) had at least one VA health encounter during one of the two time periods. Among the 3,064 Veterans still alive at Time 2, 3,032 (99\%) had a Time 2 encounter. As Table 1 shows, of those with an encounter, 85.1\% of SC+ Veterans versus $74.6 \%$ of SC-Veterans made at least one outpatient stop at a VA in the year centered on their Time 1 survey $(p<0.001)$. SC+ Veterans were also more likely than SC-Veterans to have made any stops in mental health, primary care, specialty medicine, and surgery clinics in the Time 1 year, whereas SC- Veterans were more likely to have had a mental health rehabilitation stop. This pattern tended to persist at Time 2, except for specialty medicine, where about one third of both SC+ and SC- Veterans made stops. In both time periods, among Veterans making any health care stops, the average number of stops tended to be similar across PTSD service connection status. The one exception was the rehabilitation clinics, where SC- Veterans made statistically significantly more stops than SC+ Veterans.

Table 2 shows VA hospitalizations for the two time periods. Slightly more than $10 \%$ of SC+ and SC- Veterans had any hospitalizations in either time period. SC+ Veterans were 1.9 times more likely to have had a psychiatric hospitalization during Time 1 compared to Time 2 . SC- 
Veterans were about 1.6 times more likely to have had a psychiatric hospitalization during Time 1 compared to Time 2 .

Table 3 shows Veterans' mean change in outpatient and inpatient VA health care utilization. For both SC+ and SC- Veterans, total outpatient stops decreased by an average of slightly more than 4 visits per year between the two time periods. This was probably driven by the reduction in mental health care stops: the number of mental health visits made by SC+ veterans also decreased by an average of 4 visits per year between Time 1 and Time 2 . For SC- Veterans, the decrease was slightly less than 3 visits per year. For the remaining subcategories of health care, the direction of change in utilization was the same for both groups, and the amount of change was also similar.

\section{Discussion}

Consistent with others' reports, we found that, on net, more Veterans service connected for PTSD used outpatient VA mental health services after their claims were adjudicated than did Veterans whose PTSD claims had been denied $[6,7,12]$. Most investigators have examined Veterans' post-claims' health care utilization for periods of just weeks to a few months [6-8]. An exception, Sripada et al. [13] examined Veterans' mental health care utilization for 52 weeks after they became newly service connected for PTSD or increased their PTSD disability rating. Eighty-nine percent of their participants had stable or increasing use post-claim or rating increase; however, the higher Veterans' post-claim service rating was, the less likely they were to reduce their mental health care utilization. In the present study, we showed that more SC+ Veterans used VA health care services across most outpatient domains for up to twelve years after they became service connected for PTSD compared to Veterans with denied claims. Except for the few Veterans receiving rehabilitative services, the intensity of services used within each subcategory of outpatient care appeared to be similar for SC+ and SC-Veterans. In other words, among those making any visits, SC+ and SC-Veterans had similar numbers of visits per year. Rates of hospitalizations were also comparable across the two groups, likewise suggesting similar intensities of inpatient services use.

By Time 2, which was 6-8 years after Time 1, both SC+ and SC- Veterans made fewer mental health care stops compared to Time 1, but the reduction in use was similar for both groups. As we report elsewhere [11], both groups' PTSD symptom severity improved between Time 1 and Time 2; however, the difference was clinically meaningful only for the Veterans service connected for PTSD. Thus, it could be that some Veterans stopped using or reduced outpatient mental health services at Time 2 because they no longer needed them.

The patterns of use seen here and elsewhere should reassure those who fear Veterans use mental health care solely to gain access to cash disability benefits. Our findings indicate that more SC+ Veterans use mental health care than SC-Veterans not just in the few weeks and months post-claim, but also for many years after. Indeed, perhaps the larger concern should be reserved for the SC- Veterans. SC- Veterans are often just as impaired as successful claimants but may have fewer resources [14]. 
Unfortunately, our access to Veterans' health care utilization data in this study was restricted and time-limited. Therefore, we could not test for any mediators, moderators, or confounders of the effect of PTSD service connection on health care utilization. We were unable to examine impacts of higher disability ratings on Veterans' health care utilization or to isolate the specific impact of PTSD service connection on health care utilization relative to service connection for other disorders. Nor were we able to examine gender's impact, if any, on the relationship between PTSD service connection and VA health care utilization. Compared to men, the women in this study were significantly less likely to be service connected for PTSD [10]; further, they identified particular barriers to receiving women-centric care that may have prompted them to seek mental health services elsewhere [15]. Results from this study may not generalize to Veterans with service connection for other disorders and they may not apply to Veterans from more recent conflicts. 


\section{References}

1. Veterans Benefits Administration: Annual Benefits Report: Fiscal Year 2016: Compensation. Washington DC: US Department of Veterans Affairs; 2016.

2. $\quad$ Burkett B, Whitley G: Stolen Valor, 1st edn. Dallas, TX: Verity Press, Inc.; 1998.

3. Frueh B, Hamner M, Cahill S, Gold P, Hamlin K: Apparent symptom overreporting in combat veterans evaluated for PTSD. Clin Psychol Rev 2000, 20(7):853-885.

4. Sayer N, Thuras P: The influence of compensation-seeking status on PTSD treatment: perceptions of Veterans Affairs clinicians. Psychiatr Serv 2002, 53:210-212.

5. Dept. Veterans Affairs Office of Inspector General: Review of state variances in VA disability compensation payments. In. Washington, DC: Dept. Veterans Affairs Office of Inspector General; 2005: 192.

6. Sayer N, Spoont M, Nelson D: Disability compensation for PTSD and use of VA mental health care. Psychiatr Serv 2004, 55(5):589.

7. Spoont M, Sayer N, Nelson D, Nugent S: Does filing a PTSD disability claim promote mental health care participation among veterans? Milit Med 2007, 172:572-575.

8. Black A, Meshberg-Cohen S, Perez-Ortiz A, Thornhill T, Rosen M: Veterans' compensation claims beliefs predict timing of PTSD treatment use relative to compensation and pension exam. PLOS one 2018, 13(12):e0209488.

9. Murdoch M, Hodges J, Cowper D, Fortier L, van Ryn M: Racial disparities in VA service connection for posttraumatic stress disorder disability. Med Care 2003, 41(4):536-549.

10. Murdoch M, Hodges J, Hunt C, Cowper D, Kressin N, O'Brien N: Gender differences in service connection for PTSD. Med Care 2003, 41(8):950-961.

11. Murdoch M, Sayer N, Spoont M, Rosenheck R, Noorbaloochi S, Griffin J, Arbisi P, Hagel E: Long-term outcomes of disability benefits in US Veterans with posttraumatic stress disorder. Arch Gen Psychiatry 2011, 68(10):1072-1080.

12. Laffaye C, Rosen C, Schnurr P, Friedman M: Does compensation status influence treatment participation and course of recovery from posttraumatic stress disorder? Milit Med 2007, 172(10):1039-1045.

13. Sripada R, Hannemann C, Schnurr P, Marx B, Pollack S, McCarthy J: Mental health service utilization before and after receipt of a service-connected disability award for PTSD: findings from a national sample. Health Serv Res 2018, 53(8):4565-4583.

14. Fried D, Helmer D, Halperin W, Passannante M, Holland B: Health and health care service utilization among U.S. Veterans denied VA service-connected disability compensation: a review of the literature. Milit Med 2015, 180(10):1034-1040.

15. Kehle-Forbes S, Harwood E, Spoont M, Sayer N, Gerould H, Murdoch M: Experiences with VHA care: a qualitative study of US women Veterans with self-reported trauma histories. BMC Women Health 2017, 17(1):38. 
Table 1. Outpatient Stops by Veterans' PTSD Service Connected Status ${ }^{a}$

Outpatient Stops

Time 1

\begin{tabular}{|c|c|c|c|c|}
\hline & \multicolumn{2}{|c|}{ Service Connected for PTSD ${ }^{a}$ ? } & \multicolumn{2}{|c|}{ Service Connected for PTSD ${ }^{a}$ ? } \\
\hline & $\begin{array}{c}\text { Yes } \\
\mathrm{N}=1,904\end{array}$ & $\begin{array}{c}\text { No } \\
\mathrm{N}=1,186\end{array}$ & $\begin{array}{c}\text { Yes } \\
\mathrm{N}=1,875\end{array}$ & $\begin{array}{c}\text { No } \\
\mathrm{N}=1,157\end{array}$ \\
\hline \multicolumn{5}{|l|}{ Total Outpatient } \\
\hline With any & $85.1 \%$ & $74.6 \% * * *$ & $83.7 \%$ & $77.8 \% * * *$ \\
\hline Number of stops, mean $\left(S D^{b}\right.$ & $19.4(32.5)$ & $19.6(47.9)$ & $14.8(21.6)$ & $15.4(30.8)$ \\
\hline Number of stops among those with any, mean (SD) & $22.8(34.1)$ & $26.2(53.9)$ & $17.7(22.5)$ & $19.8(33.6)$ \\
\hline \multicolumn{5}{|l|}{ Mental Health } \\
\hline With any & $70.5 \%$ & $53.4 \% * * *$ & $61.4 \%$ & $51.8 \% * * *$ \\
\hline Number of stops, mean $\left(S D^{b}\right.$ & $11.3(24.5)$ & $9.3(27.4)^{*}$ & $6.9(15.4)$ & $6.5(16.8)$ \\
\hline Number of stops among those with any, mean (SD) & $16.0(27.8)$ & $17.5(35.5)$ & $11.2(18.4)$ & $12.5(21.7)$ \\
\hline \multicolumn{5}{|l|}{ Primary Care } \\
\hline With any & $70.2 \%$ & $63.7 \% * * *$ & $76.2 \%$ & $71.8 \% * *$ \\
\hline Number of stops, mean $(S D)^{b}$ & $3.1(4.1)$ & $3.0(4.3)$ & $3.1(3.5)$ & $3.2(3.8)$ \\
\hline Number of stops among those with any, mean (SD) & $4.4(4.2)$ & $4.7(4.6)$ & $4.1(3.5)$ & $4.4(3.8)$ \\
\hline \multicolumn{5}{|l|}{ Specialty Medicine } \\
\hline With any & $34.3 \%$ & $29.7 \% * *$ & $35.7 \%$ & $34.1 \%$ \\
\hline Number of stops, mean $(S D)^{b}$ & $1.2(4.4)$ & $1.0(2.4)$ & $1.3(4.8)$ & $1.3(5.1)$ \\
\hline Number of stops among those with any, mean ( $S D)$ & $3.5(6.9)$ & $3.2(3.6)$ & $3.7(7.4)$ & $3.8(8.2)$ \\
\hline \multicolumn{5}{|l|}{ Surgical Care } \\
\hline With any & $49.7 \%$ & $41.8 \% * * *$ & $52.4 \%$ & $48.2 \% *$ \\
\hline Number of stops, mean $(S D)^{b}$ & $2.0(3.6)$ & $1.8(3.9)$ & $2.0(3.7)$ & $1.8(3.3)$ \\
\hline Number of stops among those with any, mean ( $S D)$ & $4.0(4.2)$ & $4.3(5.1)$ & $3.8(4.4)$ & $3.7(3.9)$ \\
\hline \multicolumn{5}{|l|}{ Mental Rehabilitation } \\
\hline With any & $2.2 \%$ & $3.9 \% * *$ & $1.5 \%$ & $2.9 \% * *$ \\
\hline Number of stops, mean $(S D)^{b}$ & $0.5(7.8)$ & $2.3(23.5)^{* *}$ & $0.2(2.2)$ & $1.0(14.4)^{*}$ \\
\hline Number of stops among those with any, mean (SD) & $21.9(48.0)$ & $59.0(105.6)^{*}$ & $11.4(14.5)$ & $35.6(78.3)$ \\
\hline \multicolumn{5}{|l|}{ Physical Rehabilitation } \\
\hline With any & $26.5 \%$ & $23.8 \%$ & $28.8 \%$ & $27.2 \%$ \\
\hline Number of stops, mean $\left(S D^{b}\right.$ & $1.4(5.2)$ & $2.2(15.3)$ & $1.3(5.1)$ & $1.7(9.4)$ \\
\hline Number of stops among those with any, mean (SD) & $5.3(9.0)$ & $9.3(30.4)^{*}$ & $4.5(8.6)$ & $6.2(17.2)$ \\
\hline
\end{tabular}

${ }^{a}$ Service connected status is as of Time $1 .{ }^{b}$ Includes those with zero stops in that time period.

$* \mathrm{p}<0.05,{ }^{* *} \mathrm{p}<0.01, * * * \mathrm{p}<0.001$; Compares SC+ to SC- within each time period. 
Table 2. Hospitalizations by Veterans' PTSD Service Connected Status ${ }^{a}$

\begin{tabular}{|c|c|c|c|c|}
\hline \multirow[t]{2}{*}{ Hospitalizations } & \multicolumn{2}{|c|}{$\begin{array}{c}\text { Time } 1 \\
\text { Service Connected for PTSD } \\
\text { ? }\end{array}$} & \multicolumn{2}{|c|}{$\begin{array}{c}\text { Time } 2 \\
\text { Service Connected for PTSD }\end{array}$} \\
\hline & $\begin{array}{c}\text { Yes } \\
\mathrm{N}=1,904\end{array}$ & $\begin{array}{c}\text { No } \\
\mathrm{N}=1,186\end{array}$ & $\begin{array}{c}\text { Yes } \\
\mathrm{N}=1,875\end{array}$ & $\begin{array}{c}\text { No } \\
\mathrm{N}=1,157\end{array}$ \\
\hline \multicolumn{5}{|l|}{ Total Hospitalizations } \\
\hline With any & $13.3 \%$ & $12.0 \%$ & $11.2 \%$ & $10.8 \%$ \\
\hline Number of hospitalizations, mean $^{b}$ & 0.1 & 0.1 & 0.1 & 0.1 \\
\hline Number of hospitalizations among those with any, mean $(S D)$ & $1.7(1.3)$ & $1.8(1.3)$ & $1.7(1.6)$ & $1.5(0.9)$ \\
\hline \multicolumn{5}{|l|}{ Psychiatry Hospitalizations } \\
\hline With any & $7.5 \%$ & $6.1 \%$ & $3.9 \%$ & $3.8 \%$ \\
\hline Number of hospitalizations, mean ${ }^{b}$ & 0.1 & 0.1 & 0.04 & 0.04 \\
\hline Number of hospitalizations among those with any, mean $(S D)$ & $1.7(1.2)$ & $1.7(1.2)$ & $1.8(1.9)$ & $1.4(0.7)$ \\
\hline \multicolumn{5}{|l|}{ Medical or Surgical Hospitalizations } \\
\hline With any & $7.0 \%$ & $6.2 \%$ & $7.9 \%$ & $7.3 \%$ \\
\hline Number of hospitalizations, mean $^{b}$ & 0.1 & 0.1 & 0.08 & 0.07 \\
\hline Number of hospitalizations among those with any, mean $(S D)$ & $1.4(0.8)$ & $1.6(1.0)$ & $1.5(1.0)$ & $1.4(0.9)$ \\
\hline
\end{tabular}

${ }^{a}$ Service connected status is as of Time $1 .{ }^{b}$ Includes those with zero stops in that time period. 
Table 3. Change in VA Health Care Utilization from Time 1 to Time 2 by Veterans' PTSD Service Connected Status ${ }^{a}$ Change in VA Health Care Service Connected for PTSD ${ }^{a}$ ?

p-value

$$
\text { Yes }
$$$$
\text { No }
$$

\section{Outpatient Stops}

$\mathrm{N}=1,875 \quad \mathrm{~N}=1,157$

Total number, mean $(S D)$

Mental Health, mean (SD)

Primary Care, mean $(S D)$

Specialty Medicine, mean $(S D)$

Surgical Care, mean $(S D)$

Mental and Physical Rehabilitative, mean (SD)

\section{Hospitalizations}

Total, mean $(S D)$

Psychiatry Hospitalizations mean (SD)

Medical and Surgical Hospitalizations, mean (SD)

$\mathrm{N}=1,875 \quad \mathrm{~N}=1,157$

${ }^{a}$ Service connected status is as of Time 1. Negative numbers indicate lower use at Time 2. 


\begin{tabular}{ll} 
Appendix. Outpatient Stop Codes Used to Determine VA Health Care Utilization \\
\hline Category & Stop Codes \\
\hline Mental Health & $292,502,503,505,506,509,510,512-514,516,519,522-525,529,531,533$, \\
& $538,540,547,550,552-554,556-558,560-567,576-578,580,581,590$ \\
\hline Primary Care & $170,172,290,301,322,323,348,350,703,707,710$ \\
\hline Specialty Medicine & $145,152,293,302-321,330,331,334-336,351,372,373,394,602-604,606-$ \\
& 608,610 \\
\hline Surgery & $144,149,153,291,327-329,401,403-419,421,422,426,429-433,435,436$ \\
\hline Mental Rehabilitation & $517,532,535,559,569-575,582,583,725-728,730$ \\
\hline Physical Rehabilitation & $174,177,197,198,201-215,217-220,222,223,228,294-296,417,418,420$, \\
& $423,437,439$ \\
\hline
\end{tabular}

